\title{
Endoscopic removal of an extraluminal, intrapancreatic dislocated common bile duct stone
}

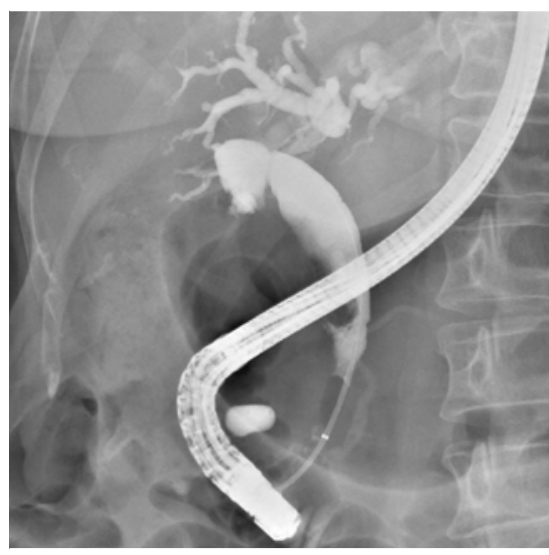

- Fig. 1 Fluoroscopy image during the first endoscopic retrograde cholangiopancreatography, showing the large common bile duct stone behind the duodenoscope.

We present the case of a 57-year-old woman who was referred for the treatment of an intrapancreatic dislocated common bile duct (CBD) stone ( $>$ Video 1).

The patient had presented 8 weeks earlier with recurrent biliary colics and obstructive jaundice due to a solitary CBD stone of $12 \mathrm{~mm}$. An initial attempt to remove the stone via endoscopic retrograde cholangiopancreatography (ERCP) with sphincterotomy and conventional stone extraction was unsuccessful owing to the size of the stone ( $\mathbf{F i g}$. 1). A 10-Fr plastic stent was inserted to secure biliary drainage. In a second attempt 4 weeks later, use of a balloon extraction catheter and dormia basket also failed. Dilation balloon-assisted stone extraction by means of balloon sphincteroplasty up to $15 \mathrm{~mm}$ was performed as a next step. A fully inflated balloon extraction catheter could easily be extracted without observing a stone. It was assumed that the stone passed unnoticed during manipulation with the dilation balloon.

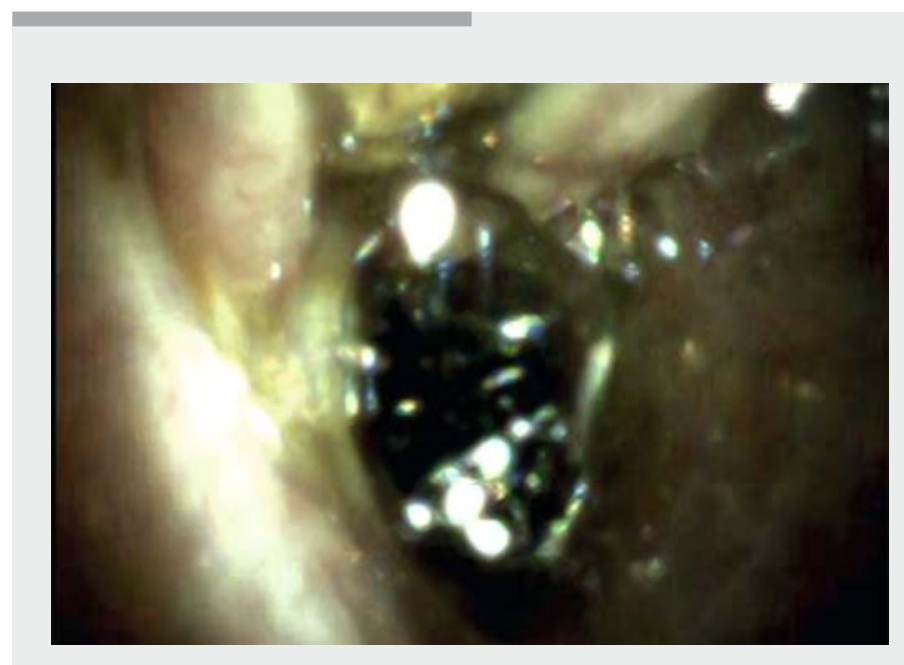

$\checkmark$ Video 1 Endoscopic removal of an intrapancreatic dislocated common bile duct stone by cholangioscopy and electrohydraulic lithotripsy.

The patient was readmitted 1 week later because she felt generally unwell and had a fever. There were no signs of jaundice, abdominal pain or tenderness. A computed tomography scan revealed that the bile duct stone, which was assumed to have passed, was in fact impacted inside the pancreas, alongside and out of the CBD ( $\triangleright$ Fig. 2 ). The patient was treated with broad-spectrum antibiotics and referred to our hospital.

Endoscopic ultrasonography confirmed the intrapancreatic impacted stone at the lateral distal side of the CBD. Cholangiography confirmed the presence of the stone in an intrapancreatic pocket ( Fig.3) and the patency of the CBD. Using single-operator cholangioscopy (Spyglass DS; Boston Scientific, Marlborough, Massachusetts, USA), we were able to fragment the impacted stone using electrohydraulic lithotripsy and remove the remnant stone fragments (- Fig.4). The large biliary defect and remaining excavation was closed off by means of a fully covered metal stent, which was removed 6 weeks later; complete regression of the defect was ob- served at cholangiography. The patient underwent a laparoscopic cholecystectomy 6 weeks later and remained well.

Endoscopy_UCTN_Code_CPL_1AK_2AC

Competing interests

None

The authors

Thomas Billiet ${ }^{1}$, Annelies Holvoet ${ }^{2}$, Sofie Decock $^{2}$, Joris Arts ${ }^{2}$, Jean-Marc Gillardin ${ }^{3}$, Philippe Van Hootegem ${ }^{2}$, Wim Laleman ${ }^{1,4}$

1 Department of Gastroenterology and Hepatology, Section of Liver and Biliopancreatic disorders, University Hospitals Leuven, KU Leuven, Belgium

2 Department of Gastroenterology, AZ St-Lucas, Brugge, Belgium

3 Department of Abdominal Surgery, AZ St-Lucas, Brugge, Belgium

4 Department Chronic Diseases, Metabolism and Ageing (CHROMETA), KU Leuven, Leuven, Belgium 


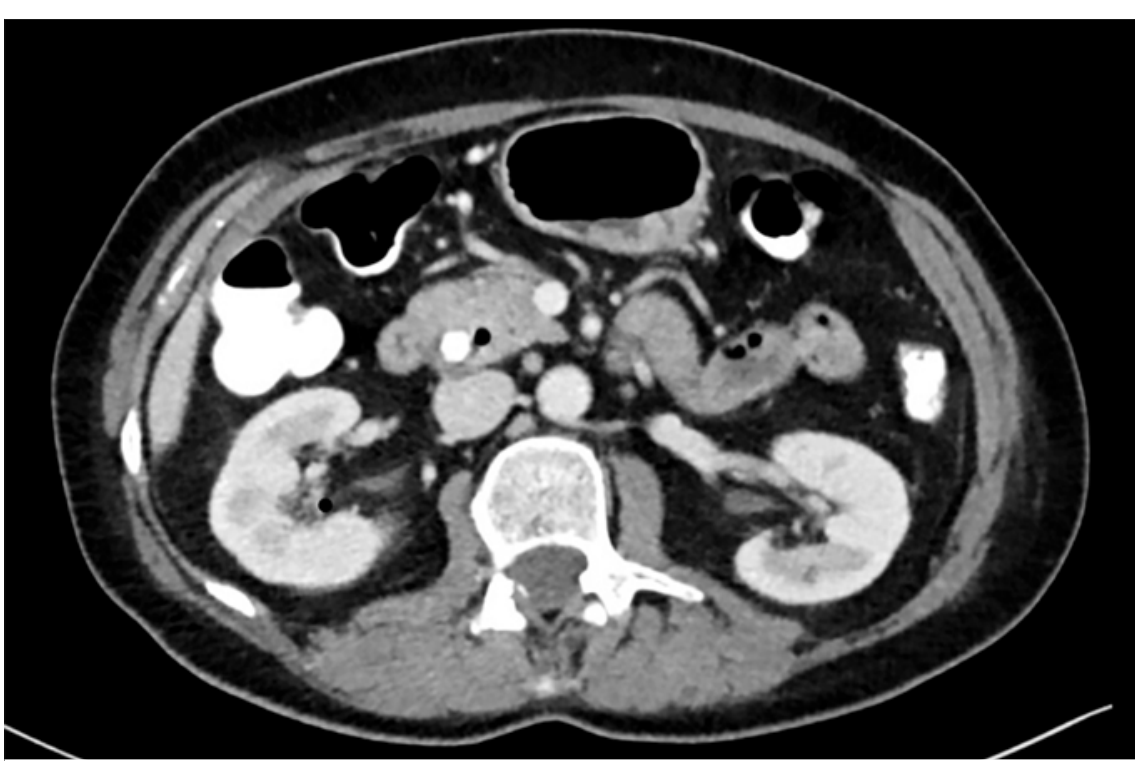

- Fig.2 Abdominal computed tomography scan after the second endoscopic retrograde cholangiopancreatography, showing the common bile duct (CBD) filled with air and, just next to it, the intrapancreatic impacted CBD stone.

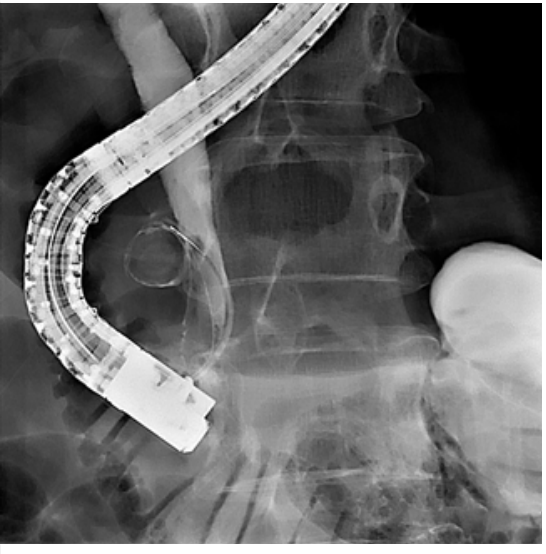

Fig. 3 Fluoroscopy image clearly demonstrating the common bile duct (CBD) stone in an extraluminal intrapancreatic position. There is no obstruction of the CBD.

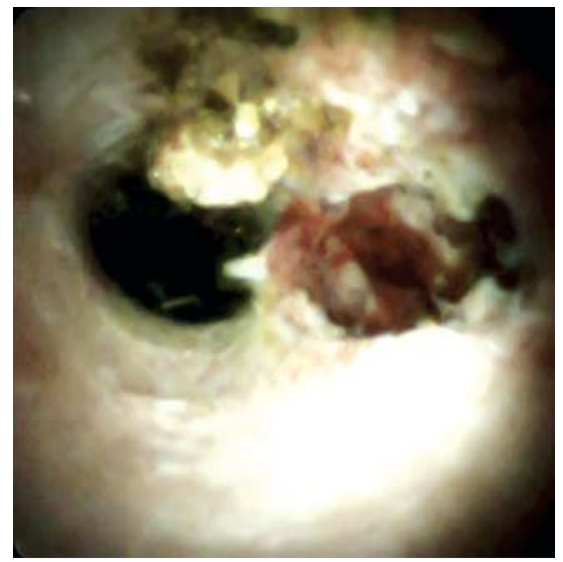

> Fig. 4 Cholangioscopy image demonstrating the lacerated bile duct wall with an intrapancreatic cavity after partial clearance of the bile duct stone with electrohydraulic lithotripsy.
Corresponding author

Wim Laleman, MD, PhD

Department of Gastroenterology and

Hepatology, Section of Liver and

Biliopancreatic disorders, University

Hospitals Leuven, Department Chronic

Diseases, Metabolism and Ageing

(CHROMETA), Herestraat 49, Leuven 3000,

Belgium

Fax: +32-16-344387

wim.laleman@uzleuven.be

\section{Bibliography}

DOI https://doi.org/10.1055/a-0992-8832

Published online: 17.9.2019

Endoscopy 2020; 52: E59-E60

(c) Georg Thieme Verlag KG

Stuttgart $\cdot$ New York

ISSN 0013-726X

\section{ENDOSCOPY E-VIDEOS \\ https://eref.thieme.de/e-videos}

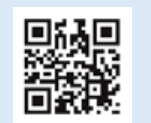

Endoscopy E-Videos is a free access online section, reporting on interesting cases and new techniques in gastroenterological endoscopy. All papers include a high quality video and all contributions are freely accessible online.

This section has its own submission website at

https://mc.manuscriptcentral.com/e-videos 